\title{
PNEUMONIA REDONDA / PNEUMONIA PSEUDOTUMORAL
}

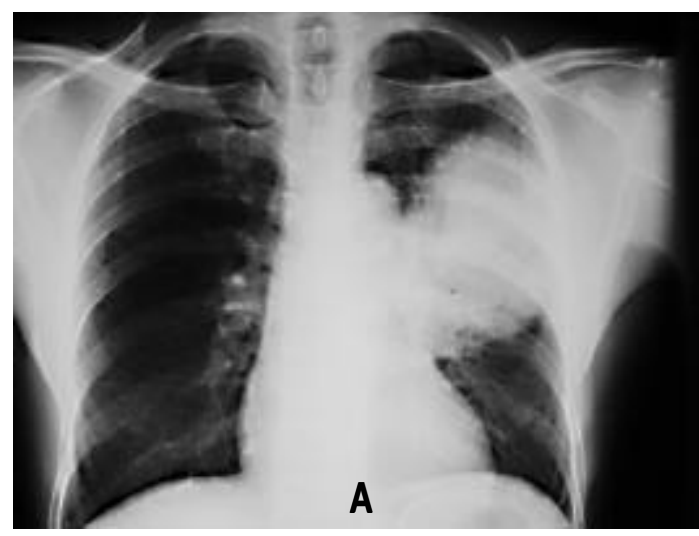

Figura A

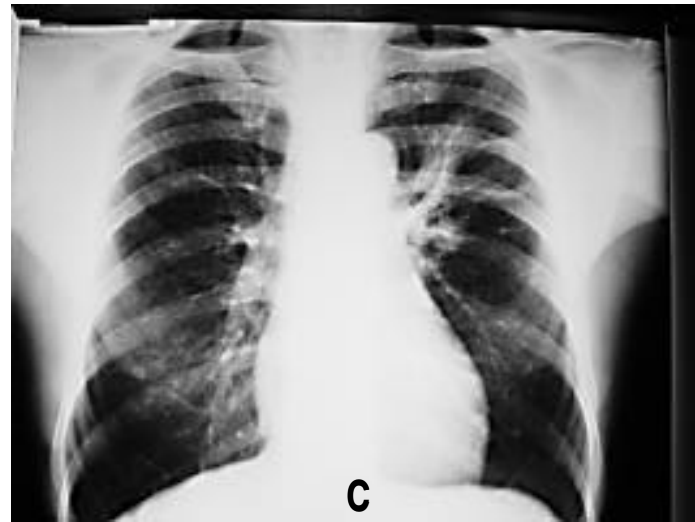

Figura C

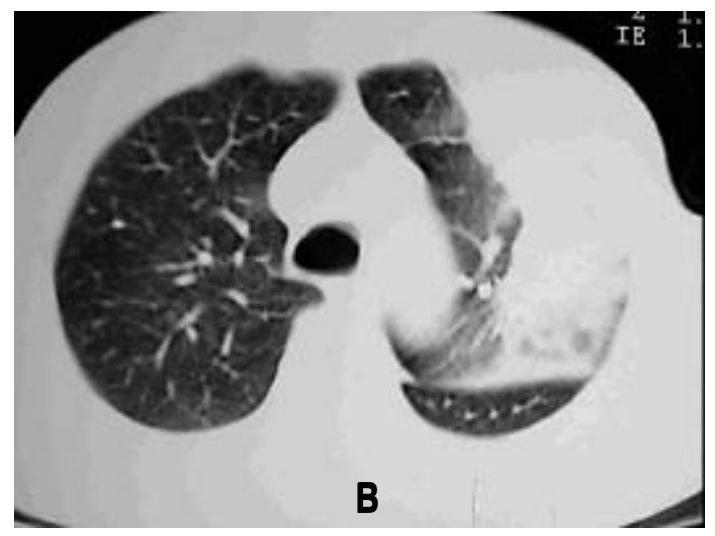

Figura B

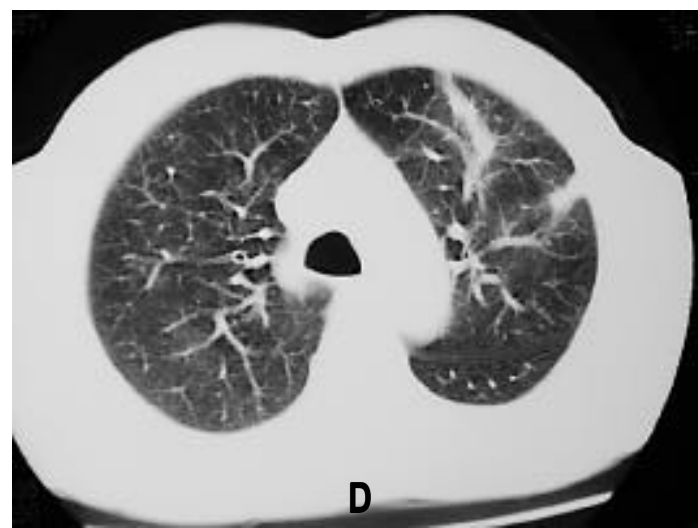

Figura D

Paciente masculino, 57 anos, tabagista de 60 anos / maço, procurou serviço médico com história de tosse produtiva com expectoração amarelada, febre $\left(38^{\circ} \mathrm{C}\right)$ e perda de aproximadamente $3 \mathrm{~kg} \mathrm{em} 20$ dias. A radiografia inicial está identificada na Fig. A, e a imagem da CT correspondente está representada na Fig. B. Após a primeira consulta foi iniciado tratamento com claritromicina por 10 dias. No retorno, apresentava melhora dos sintomas e encontrava-se afebril. A radiografia de controle após o final do tratamento encontra-se representada na Fig. C e a CT correspondente na Fig. D.

A pneumonia redonda, ou pseudotumoral, é uma apresentação rara das pneumonias. Ao encontrarmos uma imagem compatível com massa intratorácica, devemos lembrar de diagnósticos diferenciais, como carcinoma broncogênico ou mesmo teratoma. Os dados de história e exame físico devem ser utilizados para optar-se pela investigação diagnóstica ou pela conduta terapêutica inicial. Optando-se pelo tratamento empírico, o controle radiológico precoce pós-tratamento é obrigatório para a confirmação diagnóstica.

\section{Carlos Jardim}

Juliana Carvalho ferreira

Teresa Yae Takagakı

RogéRIo SOUza

Disciplina de Pneumologia - Faculdade de Medicina da Universidade de São Paulo 